\title{
Pasajes de una vuelta al mundo. El Oriente de Pedro Cubero Sebastián en su periplo universal
}

\author{
Joaquín $M^{a}$ Córdoba
}

Arbor CLXXX, 711-712 (Marzo-Abril 2005), 671-695 pp.

Entre 1671 y 1679, un sacerdote español llamado Don Pedro Cubero Sebastián, como predicador apostólico y explorador que iba a abrir camino a posteriores misioneros católicos, dio por primera vez la vuelta al mundo en sentido inverso al tradicional. Por tierra y mar, cruzando inmensos desiertos y cordilleras, mares y ríos caudalosos, durante ocho años viajó por Europa, Oriente Próximo y la India, Malaca, Filipinas y América hasta tornar a España navegando por el Atlántico. Tan singular sacerdote escondía el espíritu de un verdadero viajero y explorador, enamorado de los mundos distantes, los recónditos paisajes y las costumbres de los más diferentes pueblos. Su figura es una muestra más de la constancia y la original audacia de los viajeros españoles de su siglo.

\footnotetext{
Al refugio de Xen, a los robles mecidos por el viento, a la lluvia, al olor a tierra mojada, a la mirada de los perros, a la más profunda amistad. A Maria Eugenia, a Luis y a todo lo que permanece en el corazón de la carballeira.
}

A comienzos de los años setenta del siglo XVII, una gran barcaza de dos cubiertas y dos timones, uno por babor y otro por estribor, daba fondo en las playas cercanas a Derbent, todavía entonces bajo dominio del sha de Irán. Hombres e impedimenta empezaron a ser descargados. Tres niños de los arrabales de la fortaleza, curiosos y avispados, sentados en cuclillas, obser- 
vaban no lejos el desembarco de los viajeros. Entre éstos, un noble ruso de imponente ropaje, disponía enérgico el traslado de grandes fardos a la zona libre de mareas. Sus gestos cargados de autoridad, el desvelo de sus servidores y la atención con la que le seguía un sacerdote ortodoxo revelaban al hombre acostumbrado a mandar y a ser obedecido. A juzgar por sus ropas suntuosas -decíanse los niños entre sí-, podría ser todo un embajador del zar de Moscovia. Sin embargo, otro recién llegado bastante más sencillo, pero no por ello menos sorprendente, cautivó al pronto toda su atención. Era un hombre joven, alto y fuerte, que vestía severo ropaje, la cintura ceñida con un fajín de color, y que llevaba colgando sobre el pecho una especie de gran sebja. Aquel hombre desperezaba su espalda y sus miembros entumecidos, y mientras paseaba su vista alrededor, el viento revolvía la larga y espléndida melena oscura que le caía sobre los hombros. Aquella extraña vestidura, tan orgullosa melena y una abundante barba componían una respetable imagen, que a los pequeños hubo de antojárseles fantástica. El hombre les miró haciéndoles un gesto amistoso, pero rompiendo a reir, los niños salieron corriendo hacia Derbent contando a gritos la nueva de su hallazgo. La barcaza de Astrakán había llegado por fin, y gentes extrañas esperaban los suministros que los lugareños solían venderles.

Algunos días después, un mensajero oficial llegó al improvisado campamento organizado por los viajeros de la barcaza rusa, portando el imprescindible permiso del gobernador de la provincia que les permitía entrar en Derbent. Y los tres amigos pudieron seguir atropellados, pero silenciosos y expectantes, el paso del extraño hombre de la melena oscura, que miraba atento las murallas y las piedras de la ciudad. De hecho estaba anotando en su memoria lo que luego describiría en sus recuerdos: "Darbant es una ciudad no muy grande, sita sobre un peñasco, con fuertes muros, y torreones, hechos al modo Gentílico, todo de piedra: tiene sus troneras, por donde se disparaban las saetas: y hay algunos Epitafios en lengua Griega, en los cuales declara haber sido fundada por el grande Alejandro, en la conquista de los Scitas ó Hircanios". Y es que aquellos niños anónimos acababan de conocer, aunque no lo supieran, a uno de los más sorprendentes viajeros españoles de todos los tiempos, el sacerdote Don Pedro Cubero Sebastián, personaje más que original entre los trotamundos europeos del siglo XVII. Misionero apostólico y aventurero sin duda, entre 1671 y 1679 aquel aragonés valeroso dio la vuelta al mundo, cruzando y descubriendo en el curso de su viaje las ciudades y los paisajes del Irán safaví, más de cincuenta años después de que lo hiciera Don García de Silva. Y así lo contaría más tarde en varios libros que merecieron gran difusión, y hasta un curioso soneto preliminar de Don Pedro Calderón de la Barca ${ }^{1}$. 
Pasajes de una vuelta al mundo...

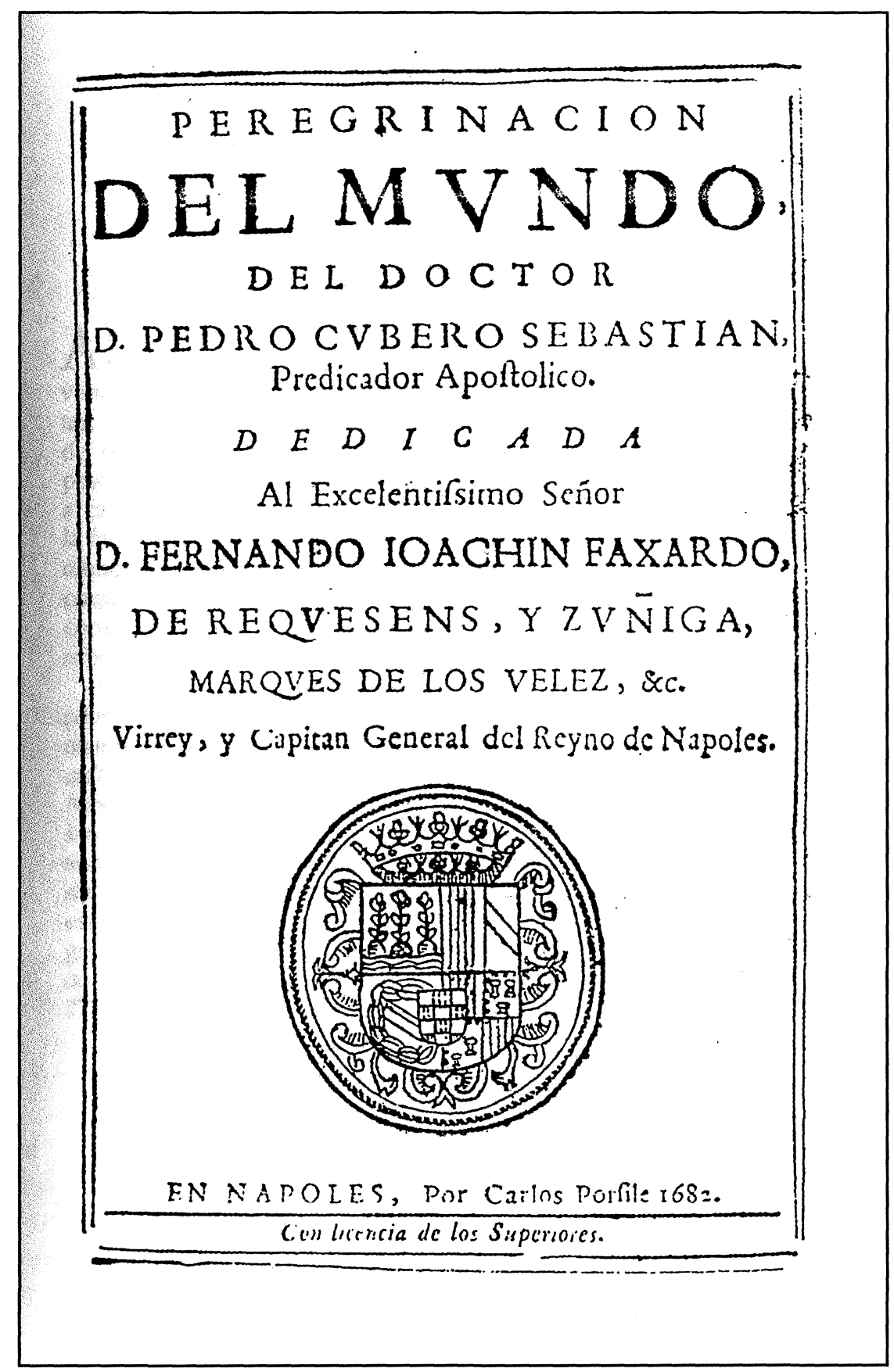

Figura 1. Portada del libro "Peregrinación del mundo", de Pedro Cubero Sebastián, publicada en Nápoles en 1682 


\section{Breve noticia de la vida de un sacerdote andariego}

"Naci en la Villa del Frasno del Reino de Aragón, una de la Comunidad de Calatayud, año de 1645". Así comienza el segundo párrafo de su libro de recuerdos, tras invocar a Dios y a la Virgen María, a quien declara protectora suya durante tan largo viaje, en el que tantas veces "me hallé con la muerte a los ojos". Pese a tan prometedor comienzo -notablemente preciso en su nacimiento y origen, como confeso sincero de la tremenda dureza de su aventura-, lo cierto es que salvo lo que él declara ahí y en otras páginas de sus obras, sabemos muy poco de la vida y carrera del singular sacerdote español. Y tampoco son muchos los estudios que se le han dedicado ${ }^{2}$, aunque su obra y sus viajes hayan merecido finalmente el recuerdo de las modernas antologías sobre viajeros europeos a Irán, por ejemplo ${ }^{3}$, lo que tras un secular y absoluto olvido, no deja de ser indicio cierto del interés real que presentan sus libros.

Nació pues en la aldea de El Fresno, provincia de Zaragoza, el año 1645. Su familia debió contarse entre las más acomodadas del reino, puesto que según escribe el mismo autor, sus padres le enviaron a estudiar al Colegio de la Compañía de Jesús en Zaragoza Humanidades y Filosofía, prosiguiendo luego estudios de Teología en Salamanca. En su libro recuerda con afecto a sus maestros, los jesuitas de Zaragoza para sus primeros pasos en la ciencia, y luego al doctor Vicente Navarrete, su iniciador en la Filosofía, y ya en Salamanca, al padre Maestro Godoy en Teología. Quizás allí sintiera la vocación religiosa y una denodada voluntad misionera pues -dice- "me incliné al misterio virtuoso de la propagación de la Fen. Ordenado sacerdote y de vuelta a Zaragoza, marchó pues a Roma con la intención de obtener del Papa el nombramiento de predicador apostólico de la Congregación de la Propaganda Fide. "Cogiendo un báculo y Breviario, me partí para Roman, comenzando así su verdadera peregrinación por el mundo. Aunque sus pasos hasta obtener la licencia papal fueran sólo el comienzo del camino, Cubero narraría con atención su viaje por España y Francia, su llegada a París donde -«apenas entré en ella, ignorante de la lengua, que viéndome en una tan confusa Babilonia, no sabía qué hacerme»-, su acogida en un seminario de misioneros apostólicos, la visita al embajador español, al gran templo de "Notradam", el Puente Nuevo y la estatua de bronce de Enrique IV, la "Rua de Santo Honore", la Plaza Real y tantos otros sitios de la misma ciudad y su entorno, concluyendo su gira con una audiencia del Delfín, que le habló en español ${ }^{4}$. Prosiguió luego su viaje por Lyon, Vienne -"ciudad muy memorable por sus antigüedades»-y Ginebra, donde con 
singular gracejo recuerda que en la puerta de la ciudad, "cuando me vieron y tuvieron por católico, que ellos llaman Papista. Comenzaron todos a mirarme como al toro en el coson. Pero salió con bien y pudo continuar su viaje cruzando los Alpes hasta llegar al Piamonte y el Ducado de Milán, del que describiría luego con esmero y admiración, "sus calles... hermosas, y espaciosas; sus palacios magnificos, sus templos admirables, y entre ellos el principal Templo, que llaman el Domo de Milán, ... admirable y preciosa fábrica, por ser todo desde sus fundamentos, de mármol, y alabastro, con tantos chapiteles y torres, que mi pluma no los puede escribir». Continuó su ruta por Parma, Módena y Bolonia, donde se reencontró con un condiscípulo suyo, entonces rector del Colegio de los Españoles, el doctor Don Juan Bernado Lafita, que le acogió con rel cariño de la crianza de nuestra niñez». Vuelto a los caminos llegaría a Florencia, "bella entre todas las demás de Italia", donde fue recibido por el Gran Duque Cosme de Médicis, que le habló de sus viajes por España, Francia y Alemania, y al que el español prometió escribir desde cualquier parte del mundo, lo que haría en reiteradas ocasiones ${ }^{5}$.

Una vez en Roma, objetivo primero de sus planes y su vocación misionera, las cosas parecen haberle ido favorablemente bien en muy poco tiempo. Tras describir su entrada, la ciudad, sus monumentos y algunas de sus circunstancias históricas, fue acogido y apoyado por el penitenciario de los españoles. Iniciado el procedimiento, obtuvo la certificación primera el 9 de febrero de 1671, y con el refrendo cardenalicio el papa Clemente X emitió a poco el decreto de "Predicador Apostólico de las Provincias Fochien, Quantum, Chamsi, de las islas de Aynán del Reino de la China y de todas las Indias Orientales», con la comisión también de hacer el viaje por tierra "para ver de la mejor forma, y manera, en que los Varones Apostólicos de la propagación de la Fe se podían introducir en las Provincias remotas Septentrionales, y Asiáticas" ${ }^{6}$. En cierta forma, esto le investía de los objetivos del misionero, pero al tiempo le obligaba a la audacia del explorador. Al ser pues su intención pasar por tierra hacia Asia, un misionero le aconsejó llevar patentes de las comunidades religiosas allí presentes, para recibir su apoyo y su protección durante el viaje. Con patentes de los benedictinos, los premonstratenses, los cistercienses, lo cluniacienses, la Compañía de Jesús, los dominicos y otras, partió de Roma un día del año 1671.

Con apenas veinticinco años de edad, Don Pedro Cubero comenzó sus ocho años de larga vuelta al mundo, que es en lo que iba a convertirse su misión apostólica y exploradora. Ocho años durante los cuales habría de enfrentarse a todo tipo de situaciones, cruzando mares y ríos, desiertos y 
cordilleras, fronteras y reinos sin fin. Conoció palacios y cárceles, fue agasajado y escarnecido, descubrió paisajes y costumbres, navegó por mares ignotos y muchas veces estuvo a punto de morir, pero al final consiguió volver a España en 1679, alcanzando Madrid a comienzos de 1680.

Aquel mismo año aparecería publicado en la capital, en la imprenta de Juan García Infançon, su Breue relación de la peregrinación que ha hecho de la mayor parte del mundo don Pedro Cubero Sebastián. Poco después se desplazó a Roma para informar al nuevo Papa, Inocencio XI, de los avatares de su misión. Más tarde, nombrado predicador y confesor apostólico de los ejércitos del emperador Leopoldo I, asistió a sus victorias contra los turcos y a la reconquista de Buda, el 2 de septiembre de 1686. La vuelta a España le permitió emprender nuevo y sorprendente viaje, dado que quiso pasara por el Rhin, Holanda, Inglaterra y Francia, hasta entrar de nuevo en la Península por Fuenterrabía. De todo ello haría narración en otro libro singular, su Segunda peregrinación de don Pedro Cubero Sebastián, missionero apostólico de Asia y Confesor General Apostólico de los Exercitos del Augustíssimo Señor Emperador contra el Turco en Vngria ... (1697). Acompañó a la reina Mariana de Neoburgo en su viaje hasta La Coruña, estuvo en las Guerras de Cataluña y en la Ceuta asediada, perdiéndose al fin su pista en los últimos años del siglo XVII. Como fechas de su muerte suelen citarse 1696 ó 1697, aunque su Epitome de los arduos viajes que ha hecho el doctor P. Cubero Sebastián en las cuatro partes del mundo: Asia, África, América y Europa, apareció impreso en Cádiz en 1700 . Pese a su manifiesta vocación religiosa y su celo misionero, y a pesar también de sus servicios político-religiosos, todo hace suponer que lo que verdaderamente dominó siempre el carácter y las ansias profundas de tan singular sacerdote fue una desbordante pasión viajera, una curiosidad irrefrenable por el mundo, un valor sin límites y una capacidad de adaptación inesperada. Por eso fue sin duda el primer español que dió la vuelta al mundo en sentido contrario al que lo hicieran Magallanes y Elcano. Y así, se diría que el viaje le permitió dar salida a su manifiesto optimismo vital y a su entusiástico afán religioso, marchando siempre al encuentro de la luz, más pendiente siempre del orto solar que del Poniente.

\section{La vuelta al mundo en,... i nueve años i}

En 1873 publicaba en París el ya famoso novelista Jules Verne, un libro que alcanzaría una fama inusitada, y que convertido en lectura emo- 


\section{Pasajes de una vuelta al mundo...}

cionada de generaciones de niños y adolescentes, terminaría por ser llevado al cine ya avanzado el siglo XX: Le tour du monde en quatre-vingts jours. Su decidido protagonista, el flemático caballero Phileas Fogg, tras aceptar una apuesta formulada en su distinguido Reform Club, emprendió una rápida vuelta al mundo acompañado sólo por su criado francés, Jean Passepartout; y aprovechando los avances de la técnica o las iniciativas de su valor y su ingenio, consiguió culminar su aventura y ganar la partida. En globo o en barco, en tren o a caballo, desde Occidente hacia Oriente, el aristócrata británico creado por la fantasía de Jules Verne, consiguió triunfar en su empeño ${ }^{7}$. Pero lo que seguramente ignoraba el novelista francés es que siglos atrás, un sacerdote español había trazado ya el camino de su héroe, acometiendo la primera vuelta al mundo conocida de Occidente hacia Oriente, cuyo recuerdo dejó en el libro que ahora nos ocupa. Eso sí, su vuelta al mundo estuvo lejos de parecerse a la rápida carrera del personaje de la novela, y el español desde luego hubo de conjurar peligros aún mayores. Porque fue una épica aventura de constancia y valentía que duró, ... nueve largos años.

En el curso de tan largo viaje, Don Pedro Cubero Sebastián debió tomar muchas notas, tal vez incluso redactó partes enteras de lo que habían de ser sus recuerdos, ya que la primera edición apareció pocos meses después de su retorno. Al cabo de dos años vería la luz en Nápoles una nueva versión, bastante más amplia ${ }^{8}$, y otra más en Zaragoza en $1688^{9}$. Complemento de éstas publicaciones fue una Descripción general del mundo y notables successos que han sucedido en el (Nápoles, 1684), que tendría a su vez otra edición en 1697, en Valencia ${ }^{10}$. Vistas las sucesivas tiradas, parece evidente que la obra de Pedro Cubero gozó de gran aceptación en la época, aunque el relato de su aventura pecara a veces de prolijo en lo secundario y escueto en lo fundamental. Pero salvo un par de versiones más o menos completas, realizadas en 1916 y 1943, hasta fechas relativamente recientes no se se ha dispuesto de una edición moderna ${ }^{11}$.

Salió de Roma por la Vía Flaminia a comienzos del año 1671, y tras visitar devotamente el Santuario de Nuestra Señora de Loreto marchó hacia Ancona, donde se embarcó rumbo a Venecia, a la que define como "una de las más ricas ciudades del mundo, ... adonde no se puede entrar sino con barcas, ó góndolas, como ellos llaman" ${ }^{12}$. El palacio de San Marcos y la Zeca, la gran plaza y el gran templo dedicado a San Marcos despertaron su asombro. Salió de allí hacia Austria, cruzando los Alpes por el Tirol, tierra que le pareció muy áspera, llegó a Viena, "muy pequeña, mas muy fuerte, rodeada con muchos baluartes, ...tiene dentro muy her- 


\section{Joaquín $M^{a}$ Córdoba}

mosos palacios". Fue a ver al embajador de España, que le consiguió audiencia del emperador: éste le dio complacido una carta de presentación para el rey de Polonia. Partió pues camino de Constantinopla y "fuéme necesario mudar de traje para pasar la Hungría, por tener la mayor parte desde Buda a Constantinopla el Turcon. Disimulando pues su condición sacerdotal, tomó una barca para seguir Danubio abajo, describiendo sus amenas orillas y la suntuosidad de las viejas ciudades húngaras, como "Estrigonia» (Esztergom) y la imponente fortaleza de una isla que llama "Gomorra» (¿Komáronvár?), cuyo jefe János Esterházy le acogió amistoso y le agasajó. En Buda, todavía bajo dominio de los turcos, se alojó en el convento franciscano; pero a partir de ahí ya no volvió a desembarcar hasta alcanzar Constantinopla, ateniéndose al consejo que le avisaba del peligro que corría si lo hacía. Sin embargo estuvo pendiente del paisaje, pues como luego escribiría, fue viendo «muchos campos muy hermosos, y muy lindos lugares, hasta que llegamos a Nandoralba (¿Nándorfehévár?); $y$ de allí pasamos a la célebre ciudad de Constantinoplan.

Gobernaba entonces el Imperio Otomano el visir Ahmad Köprülü, que como su padre el famoso Muhammad Köprülü, se obstinaba en acabar con la corrupción y detener la decadencia del imperio. Cuando Don Pedro Cubero hizo su entrada en Istanbul, ocupaba el trono de la Sublime Puerta el sultán Muhammad IV (1647-1687), que iba a intentar pocos años después la conquista de Viena. En su libro describe el viajero con atención las fortalezas y estrecho de los Dardanelos, así como el aspecto y principales monumentos de la capital otomana, sus murallas y castillos, la columna de Arcadio, el puerto de Juliano, el Serrallo que "no pude todo escribirlo, porque no me dejaron llegar a ver sino desde la puerta, distancia de veinte pasos"; pero la magia del mismo era tan grande que más adelante se decidió a contar algo merced a los informes que le dio un franco, que vestido de mujer había entrado con una judía buhoneran. Luego habla de las mil mezquitas y la principal, antiguo templo de Santa Sofía, de la que escribe con creciente asombro y minuciosa atención. Y al fin, tras despedirse de la comunidad cristiana que le había acogido, se puso en marcha camino de Polonia.

Tras bordear la tierra de Transilvania -de la que dice con asombrosa prudencia que puede escribir poco "porque la pasé muy deprisa»-, llegó al reino de Polonia, muy extenso entonces y "muy abundante, particularmente de trigo y cebada", así como en lino, cáñamo y ganadería. Estuvo en Cracovia, alojándose en el colegio jesuita de San Pedro y visitando al ciudad, su palacio y sus iglesias y conventos. Pero al llegar a Varsovia se 
Pasajes de una vuelta al mundo...

encontró con que acababa de morir el rey Miguel, destinatario de la carta que el emperador le diera como recomendación. Hubo de esperar por tanto a la elección del nuevo monarca, que resultó el célebre Juan Sobieski, a quien pocos años después deberían Austria y la Cristiandad la derrota de los turcos ante Viena. Conseguida la habitual audiencia real, prometióle el monarca su ayuda para proseguir con bien su viaje, así como cartas para el zar de Moscovia, y "otra para Schac Solimán, Rey de los Medos, y Persas". De nuevo en marcha, Cubero entró en los inmensos bosques de Lituania, siguiendo camino "tan horroroso, y oscuro de tantos bosques, que el más valeroso corazón le causa aflicción", y tras recibir en la frontera permiso de la corte de Moscú, con carta del plenipotenciario Paulo Cipriano Broztozchi para Artemión, privado del zar, entró en la inmensidad de Rusia. Al principio le pareció toda "un bosque continuado, y de tan copados árboles, y grandes, que en mi vida he visto otros mayores". Pasó por Smolensko - cuya fortaleza de ladrillo alaba-, y anduvo cien leguas entre bosques y campos nevados hasta llegar a Moscú, en compañía de un comerciante veneciano. Quince días después sería recibido por el zar Alexei I (1645-1676), en una audiencia cuyo protocolo describiría con atención, lo mismo que el aspecto y la majestad del zar, que le autorizó a ejercer su apostolado entre los latinos.

De la mano del residente polaco visitó Don Pedro la ciudad de Moscú, notando su grandeza, la simplicidad arquitectónica de las más de sus casas, levantadas en madera, las murallas del recinto palatino y la multitud de sus iglesias. La principal era la de San Juan Bautista, cercana al palacio del zar, cuya campana le pareció "de las mayores que he visto en mi vida: y cuando cayó echó abajo casi toda la torren. Llama la atención el juicio positivo que se formó del clero ortodoxo, de su condición y conducta, y también su admiración por el boato de los ritos religiosos ortodoxos en los que participaban la iglesia y el zar, como la "bendición del río Moscua, que ... la vi por mis ojos", o la fiesta del Domingo de Ramos. Pero más que la capital de Rusia le llenó de asombro la singularidad de su viaje de Moscú a Astrakán, por lo que señala que va escribir de "todo el viaje, ... por ser tan peregrino, que raro, ó ningún Español lo ha hecho», viaje que llevó a cabo en compañía de un embajador del zar que iba a Irán. Pero la relación de su marcha por las estepas meridionales rusas es una larga lista de nombres de ciudades numerosísimas, hasta alcanzar en Saratov las orillas del Volga, al otro lado del cual todavía vagaban feroces tribus de tártaros y calmucos. También le maravilló sobremanera la densidad de población vista mientras bajaba el curso del río hacia Astrakán. Y es que la multitud de aldeas y ciudades existentes en las cuatrocientas leguas recorridas hasta 
su destino le animó a extremarse en toponimia, toda vez que ren todas cuantas mapas he visto, este rio, tan célebre, lo ponen desierto y despoblado", concluyendo que "los estudiossos lo agradecerán".

Astrakán fue la última ciudad rusa que Don Pedro visitara antes de entrar en Oriente. Ganada a los tártaros tiempo atrás, las murallas de ladrillo y la asombrosa riqueza y bondad de sus pesquerías - habla por cierto del caviar y el esturión- no ocultaba la crisis de la región y la despoblación de la ciudad, porque todavía estaba reciente la rebelión del ataman cosaco "Christobal Rassin" (Stenka Razin), que "la saqueó toda, e hizo mucho daño en los naturales» ${ }^{13}$. Sin embargo seguía siendo un emporio donde convergían todas las regiones de Asia, y cuyo gobernador, hijo de un antiguo embajador ruso en España -tal vez del retratado por Juan Carreño Miranda, que estuvo en España en $1668^{14}$, le recibió con extrema amabilidad, facilitándole su labor apostólica. Tras permanecer tres meses en la ciudad llegó el tiempo de su partida, embarcándose en la gran barcaza de la que tras navegar por el Caspio y correr peligro cierto de naufragio, le vimos desembarcar en las playas de Derbent al comienzo de estas líneas.

Pasado su viaje y experiencias por Irán, las costas de Arabia, Goa y algunos sitios de la India Occidental -etapas que veremos más adelante-, salió de la barra de Goa rumbo a Ceylán, citando los reinos y ciudades que iba distinguiendo desde su nave, como la ciudad de Cochín "la principal ciudad de toda la costa: que la poseían los Portugueses, mas hoy la tiene el holandés". Con viento favorable doblaron el Cabo de Comorín, ya camino de la gran isla de Ceylán, "paraíso del Asia y con razón". A vista de tierra describe el autor la isla "de las deliciosas, y amenas que tiene el mundo: porque antes de entrar en ella, desde la misma mar se percibe un aire olorífero, y suave, que consuela todos los sentidos". Habla de la riqueza y variedad de sus árboles como el de la canela -que describe por vez primera en la historia de la Botánica, notando su proximidad al laurel-, de sus piedras preciosas tan variadas, como rubíes, jacintos, zafiros, topacios, granates y esmeraldas, de las perlas cogidas en sus aguas -las mejores de Oriente-, de sus elefantes, fuertes, poderosos e inteligentes hasta el asombro, lo que avala con anécdotas enternecedoras. En Colombo, colonia holandesa entonces, confesó y dijo misa a los católicos, aprovechando la vista gorda que el gobernador quiso hacer, pues resultó amistoso y notablemente abierto. Pero no era así lo habitual, siendo los administradores coloniales de los Países Bajos bastante más estrictos con él y con los naturales, y Don Pedro pudo comprobar cómo eran aborrecidos los holandeses por católicos e "idólatras", los unos por la prohibición hecha al catolicismo: los otros, por impedir cualquier comercio fuera del monopoliza- 
do por la Compañía Holandesa de Indias. De tal suerte, los holandeses «no predominan más que aquello, que coge la artillerían, ocurriendo lo mismo en Batavia y Malaca. Hecho a la mar de nuevo desembarcó en el extremo sur de la isla, en Gali (Galle), cuya autoridad le «miró con muy malos ojos: mas yo le dije en lengua Francesa (que la entendía muy bien, porque él era Valón) que yo era un Padre Español, que pasaba mi camino, y que mi intención no era más, que ir a saludarle: y que si no tenía gusto, que yo quedase en tierra, que me volvería a la naom ${ }^{15}$. Tranquilizado el holandés, pudo Don Pedro ir por aquella zona de la isla, y gracias a un católico valón, incluso decir misa e impartir los sacramentos a escondidas.

Prosiguió su viaje haciéndose a la vela, y tras navegar con vientos favorables de popa llegó a Nagapatan (¿Nagappattinam?), en la costa malabar del continente, donde los daneses tenían una factoría. Más tarde alcanzó Madastra Patan (¿Madrás), dominada por los ingleses. Entre medias de su relato introduce la narración de una aventura sufrida, que pudo ser la última de su viaje, cuando quiso ir a las Maldivas para atender a los católicos. Y es que apresado su barco por piratas, él y sus compañeros de navegación fueron vendidos como esclavos en la isla principal de las Maldivas. Tras algún tiempo pasado al servicio de "un negro Malabar", la esposa de su dueño terminó por ponerle en libertad, pudiendo regresar Don Pedro a Madastra Patan. De nuevo allí visitó los sitios relacionados con Santo Tomás, mostrándose por cierto muy comedido con reliquias y supuestos lugares santos, siguiéndose luego sus visitas pastorales y los habituales quiebros con las autoridades coloniales de Paliacate (¿Pulicat?), y ya en la costa de Bengala, por diferentes ciudades que va nombrando. Mas la viva controversia tenida con un predicador calvinista le obligó a partir nuevamente, haciéndose a la mar rumbo a Malaca. Tras cruzar el Océano Índico, su buque entró por el estrecho de Achen -hoy de Malaca-, " «entre la tierra firme de Malayos, y la Isla de Achen", la actual Sumatra. Una vez en Malaca visitó al gobernador holandés, Baltasar Boort, con quien llegó a tener amistad. Era éste hombre afable, que no puso empeño alguno en impedirle el ejercicio de su ministerio: «yo bien sé, que V. m. dice misa, predica, y bautiza, mas yo no quiero hacerle daño, sino decirle, que lo haga cautamenter. Pero habiendo tenido que irse a Batavia, un nuevo gobernador, casado con la hermana del pastor calvinista, decidió poner fin a la situación. Limitado y controlado en sus movimientos, algunas disputas verbales con el pastor hicieron que las cosas se pusieran tan difíciles que acabó en prisión. Después de varias audiencias públicas en las que se defendió con ardor, una pesada multa y cuatro meses de prisión, Don Pedro fue desterrado y obligado a embarcar en un navío que iba a las Filipinas. 
682

Joaquín $M^{a}$ Córdoba

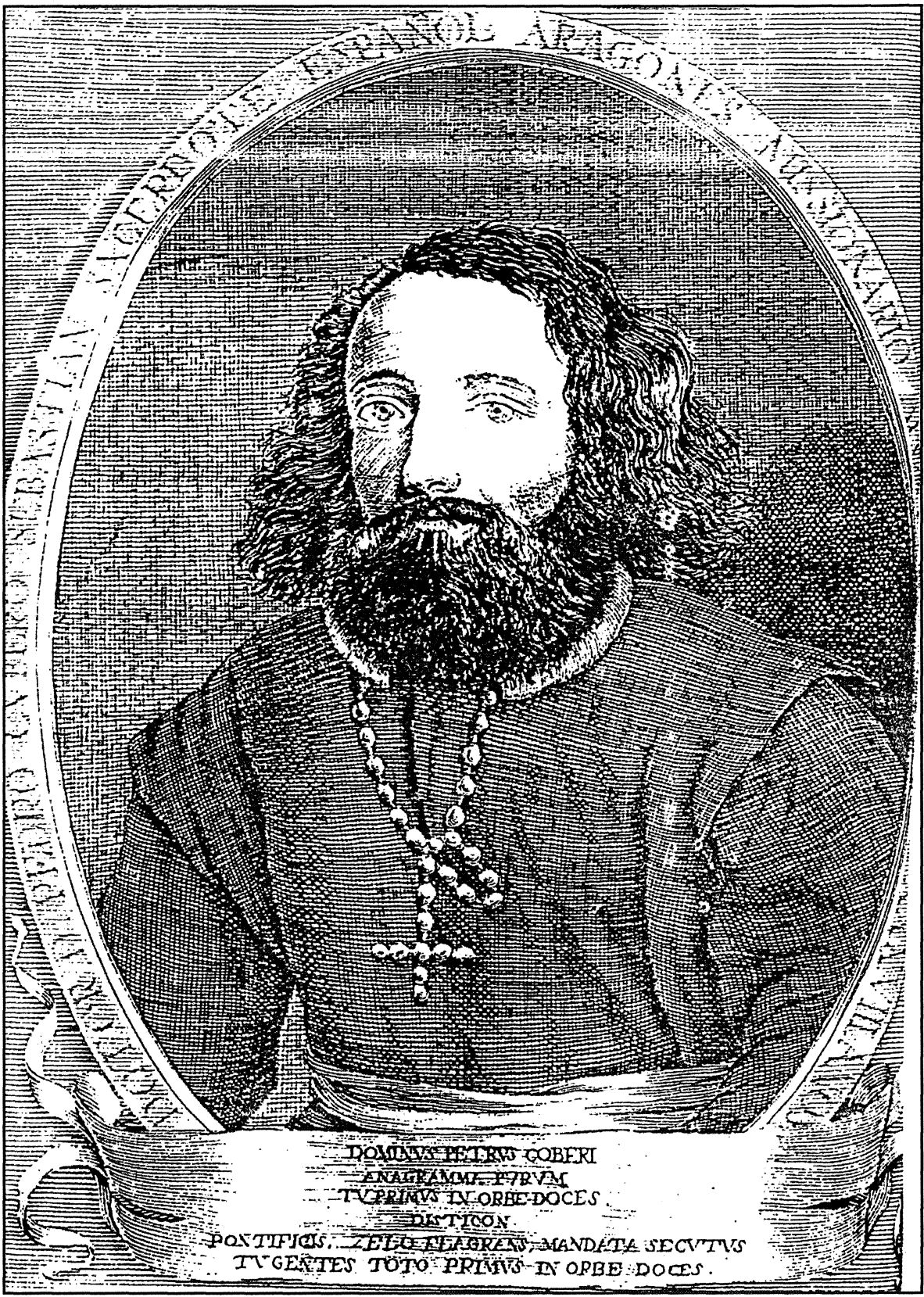

Figura 2. Retrato de Pedro Cubero que figura en la edición de Nápoles (1682) 


\section{Pasajes de una vuelta al mundo...}

Así expulsado no tuvo más remedio que poner proa a Manila, arrostrando nuevas y terribles experiencias, como un tremendo temporal en el estrecho de Singapur, en el que a punto estuvo de naufragar. Salvados todos, continuó viaje por el Mar de China Meridional, citando islas y aguadas, hasta que por fin avistaron las Filipinas y el puerto de Cavite, "tres leguas de la ciudad de Manila en una punta", astillero para los galeones que iban a Acapulco. Recibido amablemente por las autoridades locales, se alojó primero con los dominicos, y un día después fue a visitar al gobernador Don Francisco Coloma, al que hubo de narrarle "todas mis peregrinaciones, trabajos, y calamidades" por las que se había visto finalmente obligado a buscar último refugio en tierras españolas. Un paisano suyo, oficial real y contador, llamado Don Francisco Antonio de Egea, le acogió en su casa y con él estuvo todo el tiempo que permaneció en las islas. Ejerciendo su ministerio estaba cuando fue testigo del gran terremoto del 29 de noviembre de 1677, una de las pocas fechas precisas que Don Pedro facilita en su libro. La descripción del movimiento de tierra, el miedo sufrido por la gente y las destrucciones ocasionadas resulta francamente curiosa, al igual que su intervención en el rescate de una mujer y sus hijos sepultados por los escombros.

Después de predicar en distintas provincias y de vuelta a Manila, la Real Audiencia consideró que era importante que volviera a España para dar noticia de su asombrosa peregrinación, pues como dice más adelante "porque aunque otros han dado la vuelta al mundo, ha sido por mar, como se cuenta de Sebastián Cano y de Francisco Draque: mas yo he dado vuelta al mundo, habiendo andado la mayor parte por tierran; y aunque según declaró ante los oidores, tenía por intención pasar a China, decidió obedecer y marchar a España por el Pacífico, América y el Atlántico.

Tras describir las islas con detalle, dedica el viajero su capítulo XLI al "poderoso imperio de la China", recogiendo datos muy precisos e interesantes sobre el país, sus provincias y reinos, sobre sus ciudades -muy minuciosa, por cierto, la descripción de Pekín- y sus magníficos edificios, sobre sus gentes y costumbres, su religión y su medicina - «los Médicos de esta tierra son Arbolarios»-, sus artes como la cerámica y la porcelana, que dice hecha de "un barro muy recio, y tan fuerte como pedernal». Aunque no llegó a estar en China, es obvio que su deseo de ir a ella debió ser muy fuerte, por lo que al menos quiso incluir en su libro la evocación de lo que sólo las circunstancias le impidieron conocer personalmente. Los capítulos XLII y XLIII los dedica a la Tartaria y sus costumbres y a las guerras habidas entre chinos y tártaros, y el siguiente, a la historia y descripción de las Islas Molucas. Comienza sus páginas con otra precisión 
cronológica, cuando dice: "año 1678, hallándome en las Islas Filipinas, vino a Manila un Embajador del Rey de la Isla de Tidore, una de las principales de las Molucas, que otro tiempo fue de Españan, tratando entre otras cosas del envío de sacerdotes católicos. Y allá fue nuestro buen Don Pedro Cubero, en compañía de un jesuita llamado Padre Claret, alcanzando las islas tras nueve días de navegación.

Acabada su misión y de vuelta a Manila, parece que aquel mismo año tomó plaza en el famoso galeón de Manila que, bajo el mando de Don Felipe de Montemayor y Prado salió de Cavite "a veinte y cuatro de Junio, a las cinco de la mañanan. La navegación por el Océano Pacífico fue tremendamente dura, zarandeados por furiosos temporales, sufriendo varios avisos de naufragio y enfermos muchos del "Berbén, ò mal de Loandan - el mismo que costara la vida años antes, a otro de nuestros grandes viajeros a Oriente, Don García de Silva y Figueroa-, de tal suerte que "nos sucedió echar tres, ó cuatro muertos al agua cada día: de tal manera, que en menos de quince días echamos noventa y dos muertos". $\mathrm{Al}$ descubrirse el día 27 de noviembre señales de la proximidad de tierra, se puso en marcha una curiosa costumbre de la marinería. Consistía ésta en hacer un juicio burlesco al almirante del navío, al piloto, a Don Pedro en esta ocasión -porque usiempre les andaba reprendiendo: y que era el Lazarillo de la muerten-, condenándolos a dar a la tripulación chocolate a uno, bizcocho al otro, dulces y otras cosas. La tradicional fiesta era símbolo de la alegría que embargaba a los supervivientes de la terrible navegación del Galeón de Manila, tras más de cinco meses sin ver "otra cosa que cielo y aguan. Y así, a comienzos de diciembre consiguieron por fin echar el ancla en el puerto de Acapulco. Permaneció allí cuatro meses, en casa de otro paisano, también contador y oficial real, llamado Don Martín Calvo, hasta que el arzobispo de México y virrey de la Nueva España le mandara licencia. A comienzos de mayo recibió la orden de trasladarse a Veracruz. Cruzando montañas y valles, pasando por ciudades hermosas y sorprendentes, narrando curiosas situaciones, como la multitud de mosquitos que atacaban a los viajeros $-\mathrm{y}$ de cuyas picaduras curó con zumo de limón-, alcanzó por fin la bella ciudad de Veracruz y su puerto. Tras una breve estancia, el almirante Don Diego de Córdoba dio la señal para la salida de la flota, embarcándose Don Pedro en el galeón Santísima Trinidad, capitana de las naos de azogues. A últimos de julio entraban en el puerto de la Habana, que "ses muy amena, y hermosa ciudad, tiene muy anchurosas calles", donde permanecieron nueve días, y hechos de nuevo a la mar, en un mes de navegación venturosa llegaron sin novedad al puerto de Cádiz, dando así final Don Pedro Cubero Sebastián a 
Pasajes de una vuelta al mundo...

su peregrinación por el mundo. Tiempo después, el inquieto sacerdote presentaría al rey Carlos II un memorial, que es resumen sintético de su viaje $^{16}$. Y es que mucho antes de que lo hiciera el imaginario héroe de Jules Verne, aquel sencillo sacerdote español había sido capaz de circundar el globo, fiado tan solo de sus propias fuerzas y su tesón. Había dado una vuelta al mundo sin precedentes, y como tantos otros viajeros españoles de aquellos siglos, había escrito su nombre en la crónica de los titanes.

\section{Por las rutas de Irán, Arabia y la India}

Aunque portentoso en todos sus extremos, el viaje de Don Pedro Cubero Sebastián nos interesa especialmente ahora por el tramo seguido a través del Irán safaví, por su navegación a través de los mares de Arabia y por su estancia en Goa, cincuenta años después que Don García de Silva transitara idénticos caminos, surcara las mismas aguas y visitara iguales ciudades. Y nuestra historia ha de volver de nuevo a las playas de Derbent en el Caspio, donde empezara la aventura irania de nuestro viajero.

Por aquel tiempo, la situación política europea había cambiado notablemente en beneficio de Francia, y aunque España siguiera siendo una potencia respetable, la lista de viajeros llegados a Irán en la segunda mitad del siglo XVII revela bien a las claras quién tenía la iniciativa ${ }^{17}$. Cuando Don Pedro entraba en la fortaleza de Derbent, se encontraba en Irán el francés Jean Chardin -que haría luego una detalladísima descripción de las ruinas de Persépolis ${ }^{18}$, y otros que si bien residían por aquel entonces en Aleppo, como el veneciano Ambrogio Bembo o el francés François Pétis de la Croix, no mucho después cruzarían las mismas sendas que Don Pedro ${ }^{19}$.

Pues bien, pasados algunos días en las proximidades de la fortaleza de Derbent, con permisos del gobernador de la provincia, y llegada la caravana de camellos y caballos con la que iban a viajar, se pusieron en marcha siguiendo la orilla del Caspio hacia el sur, "y era gusto el ver muchos arroyos, que entraban en él, que bajaban de aquellos montes de Armeniam. Durante siete leguas fueron marchando por aquella costa, hasta que en un punto que le causó asombro por la abundancia de rosas y otras flores, dejaron la ribera internándose en las fragosas montañas camino de la ciudad de Chamake, "peladas de árboles, pero muy frondosas de hierba, porque la tierra es muy pingüe, y crasa, y apacientan alli mucho ganado", donde vio por vez primera los "carneros tan prodigiosos de Ar- 
menia, y Persian. Tras cuatro días de viaje llegaron a la ciudad, que acababa de sufrir los efectos de un terremoto, "que era lástima el verla", aunque tenía muchas tiendas de mercaderes persas, y en cuya plaza se vendían todo género de frutos, legumbres y carnes. Permanecieron allí dos meses, a la espera del protocolario permiso del sha -el gran Sofí, que dice Don Pedro-, que estaba entonces en Casmín (Qazvin). Aprovechó el tiempo para visitar la ciudad y sus alrededores, así como para relacionarse con los cristianos armenios y georgianos que allí habitaban, y con un obispo suyo con el que departió gustoso muchas veces. Recibido por fin el permiso de la corte del sah, la caravana se puso en marcha, viajando de noche a causa del calor, lo mismo que cincuenta años atrás hiciera muchas veces la de Don García de Silva. Durante el largo y fatigoso viaje observó con curiosidad y asombro las costumbres de los camellos, y la forma en que el Charbata -"que es lo mismo que nuestro arriero»- los cargaba, cuidaba y dirigía. Llegaron a Ardibil (Ardabil), "hermosa ciudad de la Armenia, muy rica por sus tejidos y sedas», en donde hubieron de hacer parada, al hallarse enfermo el embajador ruso, y paseándose por la ciudad, tuvo la sorpresa de encontrar a "un monje Basilio ...que me habia visto en Roma, y me hizo mucho agasajo llevándome a su Monasterio", y durante los diecinueve días que allí tuvieron que estar, tuvo con él "muchas pláticas ... en lengua italiana acerca de nuestra Religión, y sus ritos", e informado de sus planes, el monje le dio una carta para Macario, patriarca armenio residente en Qazvin.

Recuperado el embajador y puestos de nuevo en camino, a la salida de Ardabil tuvo lugar una disputa entre el emisario del zar y un halconero mayor ruso, que al frente de un grupo de treinta jóvenes era portador de otras tantas aves de caza, que el zar mandaba como regalo al sha. Fue tal la disputa -porque el halconero no quería someterse a las órdenes del embajador- que estuvieron ambas partes a punto de sacar la espada, teniendo que poner paz el bueno de Don Pedro y un noble persa enviado por el protocolo del sha. Así andando llegaron por fin a Qazvin, tras pasar por una región que al decir de nuestro viajero "no hay ciudad, ni lugar de consideración, porque los que hay son lugares muy pequeños: árboles muy raro es el que se ve, todos son campos, que en parte de ellos se coge trigo, y en otros algodón". Levantaron sus tiendas fuera de la ciudad, y al día siguiente vino a recibirles un gran cortejo de nobles persas "con muy hermosos caballos enjaezados a lo Pérsico, y ellos muy bien compuestos: salieron también muchos rústicos con diversos instrumentos, y para nosotros nos sacaron muy lindo caballos". Y así acompañados y festejados entraron los viajeros en la vieja ciudad de Qazvin, donde entonces se en- 
contraba el monarca, lo mismo que muchos años antes le ocurriera al embajador de Felipe III.

Resultó ser aquel día una alegre fiesta en la ciudad, cuyos comerciantes cerraron sus tiendas, juntándose la población para asistir al desfile de los embajadores y viajeros, camino de las casas que les habían asignado como residencia. Tras descansar tres días de las fatigas de la ruta, un maestro de ceremonias del palacio del sah les previno que al día siguiente serían recibidos en audiencia. Llegada que fue la jornada, Don Pedro asistió al protocolo que organizó la procesión, todos montados en "hermosísimos caballos", llevando los servidores las cartas de las que eran portadores brazo en alto, según la costumbre, "para que todo el pueblo las viese, y las venerasen. Iban delante muchos nobles persas, luego muchos músicos con sus instrumentos, y ante los embajadores, su séquito y él mismo -como emisario de la Congregación-, "dos Alicalicanes muy ricamente aderezados al modo Pérsico, y en la mano llevaba cada uno un bastón de ébano con su casquillo de oron. Tras desfilar por muchas calles de la ciudad, entre los gritos y la algazara del pueblo que les daba la bienvenida, llegaron a la ancha calle que llevaba al palacio, bordeada por sendas "hileras de árboles muy altos y encopados, que a mi parecer eran álamos blancos".

Recibidos al fin por el sha, tras entregar el embajador ruso sus regalos, presentó Don Pedro los suyos -un "hermoso reloj de filigrana de plata sobredorada...: dos Manicordios, todos embutidos de ébano y marfil ... $y$ dos muy hermosas esmeraldas»-, y después del ruso le tocó al español acercarse al sha. A través del intérprete atendió a sus preguntas, solicitándole que se respetaran los antiguos privilegios que sus antecesores habían otorgado a "los Padres Misionarios Apostólicos de la Persia", lo que concedió el sha, y tras interesarse por su amigo el rey de Polonia, y por los planes de Don Pedro - que le dijo tener pensado luego viajar a la India-, acabó la audiencia real. Describe luego nuestro sacerdote el salón en el que se desarrolló la audiencia, el trono, las vestiduras del sha Sulaimán (1666-1694) y su aspecto: "me pareció un hombre de treinta y seis años: la barba negra, blanco de cara: ojos negros, y hermosos". En los jardines inmediatos se organizó después un banquete, al que asistió el monarca, si bien permaneció a una distancia de catorce pasos. Sobre ricas alfombras se asentaban el embajador ruso, luego Don Pedro e inmediato a él, uno de sus compañeros, del que por vez primera nos da interesantes datos, al decir que "era Italiano, hijo de la ciudad de Venecia, llamado el Padre Sebastián Cabañoli, varón de muchas prendas, y Sacerdote muy virtuoso, y que me siguió gran parte de mi peregrinación, hasta que mu- 
rió en este virtuoso ejercicio en la India Oriental en la ciudad de Goa, en el Hospital Real, que gobernaban los Padres de la Compañian. Mientras comían, muchos músicos "con diversos instrumentos cantaban a su usan$z a$ Pérsica". Y así, cincuenta años después venía a repetirse, aunque con menos intimidad y largueza, la cena que el sha Abbás ofreciera al embajador Don García de Silva.

En el capitulo XXIX de su libro describe Don Pedro Cubero la ciudad de Qazvin, en la falda de una pequeña sierra, sus calles cubiertas, llenas de tiendas, la gran plaza, las casas de adobe y el suntuoso palacio del sha. $\mathrm{Y}$ tras algunas cosas curiosas entonces acaecidas -como la muerte que dio el mismo monarca y por su mano a su "Capitán General»-, recibido el privilegio sellado que mandaba no se molestase a los religiosos y a los demás cristianos europeos, con permiso de la corte partió de allí camino de Isfahán, en compañía de mercaderes armenios, por la misma pista que decenas de años atrás transitara la embajada española. Destaca en la ruta "dos ciudades muy buenas", que llama Scarbach y Cazan, y tras pasar "sierras tan ásperas, y nevadas, ... donde hace tanto frío y aún más que en el puerto de Guadarrama" por las que se cruzó con un enviado portugués y con el que habló en buena inteligencia, llegó a la ciudad de Isfahán.

Reconociéndola como una de las más grandes y bellas ciudades del mundo, "aunque entre ellas (se cuente) Constantinopla", la describe despaciosamente, señalando los barrios de Sulffa (Yulfa) -donde habitaban los cristianos armenios y tenían muy buenos templos, como el que asistía su Metropolitano-, barrio que le parece "tan grande como la ciudad de Zaragoza", el de Thauris, semejante en tamaño, y el de los Gauros, "antiguos infieles de la Persia, que desde el tiempo del Rey Ciro, y Darío, adoran el sol, y el fuego, guardándolo perpetuamente sin extinguirlon. Destaca sus edificios y espacios, como la gran plaza "a quien ellos llaman Meylan", con sus seiscientos noventa pasos de largo, sus acequias y árboles, las suntuosas mezquitas y el palacio del rey -cuyo interior se adornaba con muros dorados y "aunque hermosísimas pinturas, todas son lascivas y deshonestas»-, a cuya puerta había cuatro piezas de artillería con las armas de Felipe II de España, "que trajeron de la pérdida, y ruina de la tan desgraciada ciudad de Ormuz». Escribe también de la magnífica calle de dos leguas de largo, con jardines y muchos árboles, flores y frutos. Fraternalmente recibido en los diferentes conventos, donde participó el privilegio concedido por el sha, y después de visitar todos los rincones de la ciudad y conocer distintas costumbres, a lo que le llevaba su natural curiosidad e interés por todo, salió de la famosa Isfahán camino de Bandar Abbás. 
Pasajes de una vuelta al mundo...

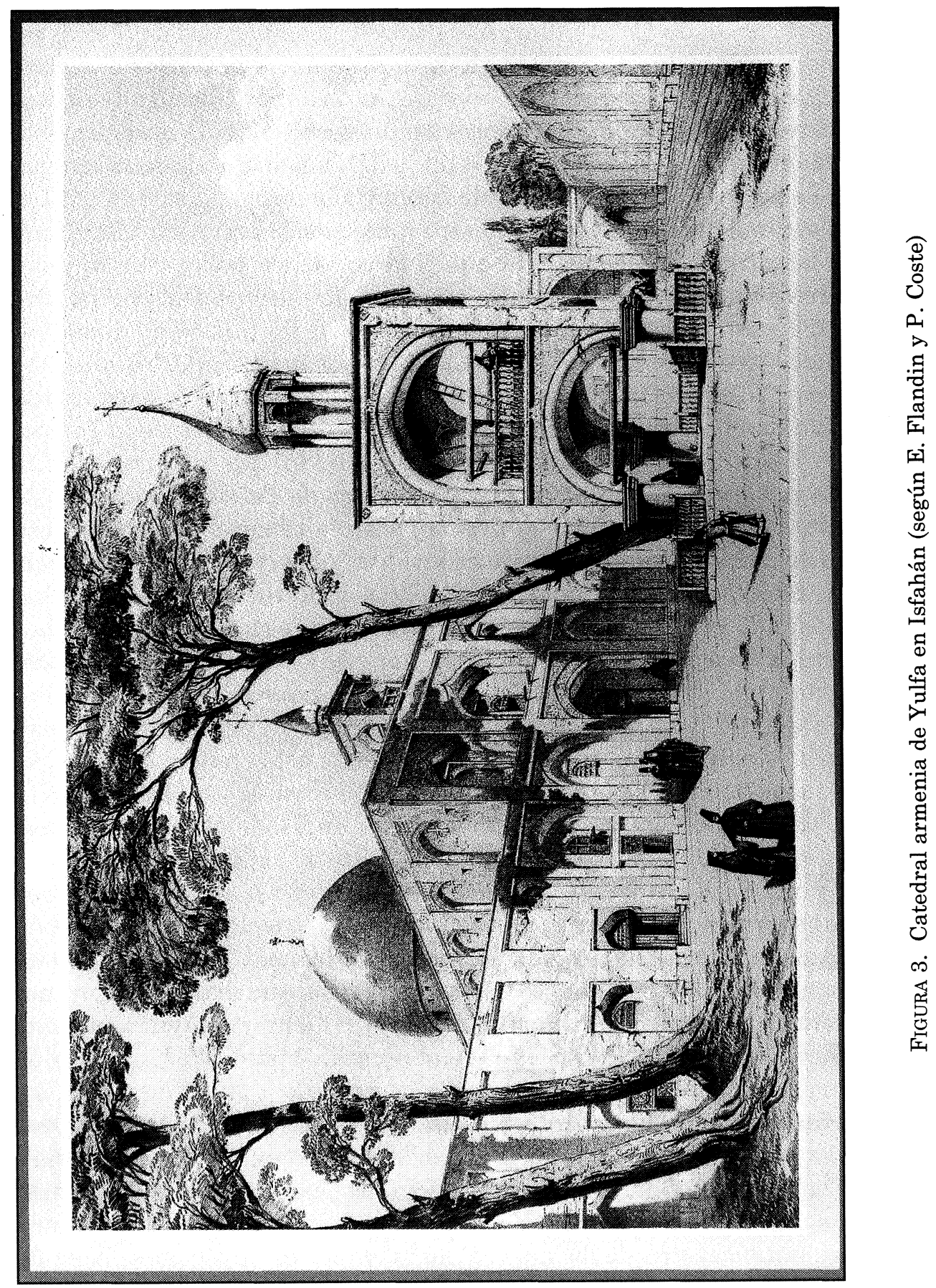


En el curso del viaje, dice que "antes de llegar a la ciudad de Syras, en un lugar, llamado Cehilminar, que distará cuatro leguas de Syras, me detuve por venir muy fatigado: ... Al lado derecho se ven unas antiguas ruinas, que se reconoce haber sido obra de los antiguos Gentiles", sin acotar mayor comentario sobre las impresionantes ruinas de Persópolis, asociadas ya entonces y para siempre -aunque Don pedro Cubero lo ignorara-, con la persona de Don García de Silva y Figueroa.

Una vez en Shiraz, escribe nuestro viajero con error evidente, que ésta era la antigua Persépolis, aunque él la vió -dice- pobre y arruinada, y que otros opinaban que "este no es el sitio de la antigua Persépolis; sino que dista cuatro leguas de allí", considerando al fin que como debía ser tan grande, "parece tener algún fundamento por las grandes ruinas, que alli se ven". Y escribe también que los Padres Misionarios le aseguraron haber oído muchos veces a los "Gauries, idólatras antiguos de la Persia, que ellos desde sus antecesores habian observado, que alli era el sitio donde reinó Ciro, Dario, y otros antiguos Reyes de Persian. Habiendo de partir contra su voluntad, por la prisa que decía tener el Charbata, prosiguió la marcha pasando valles y montañas, observando las aldeas de gentes turcomanas que sembraban algodón, y de un sitio llamado Selbistán pasando por otro llamado Pasargada "donde cuentan los antiguos haber estado el sepulcro del Rey Ciro: y aquí hay un hermosísimo ciprés muy copado, que algunos Gentiles idólatras lo adoran, y veneran". Comentario que no deja de sorprender, pues se fijó en el magnífico ciprés sin reparar siquiera en la impresionante fábrica del sepulcro de Ciro. Siguieron luego su ruta por la ciudad de Lara, "hermosa y de buenos edificios", y por camino muy seco, una jornada antes de llegar a Bandar Abbás, desde un alto descubrió la mar de Ormuz, experimentando gran alegría, pues "hacía cerca de dos años, que caminaba por tierra, ...con que ya deseaba entrar en la mar".

En Bandar Abbás fue acogido por el cónsul francés, y sabedor de que en el cercano Bandarcongo había surtas unas naos que iban al Mogor, navegó hasta aquel otro puerto, donde le recibió el factor portugués, Manuel Rodríguez de Aguiar. A la espera de embarcarse, visitó la isla de Ormuz y la ruina del antiguo presidio portugués, y estando a punto de partir llegaron cuatro naos de la armada de Goa, en las que prefirió embarcarse. Con estas naos y como capellán, acompañó al corso que la armada dirigida por Don Juan de Saà y Sotomayor hacía por las aguas del mar de Arabia. Tras distintas aventuras pasó a la costa de la India, desembarcando en Surat, entonces uno de los más célebres emporios de Oriente, llena de mercaderes de todas las naciones, "porque allí no falta el Inglés, el Ho- 
landés, el Hamburgués, el Francés, el de Dinamarca, el Suecés, el Veneciano, y Genovés, el Turco, el Persa, el Árabe, el Chino, el Japón, y el Español: ...pues no hay nación por toda la redondez del Orbe, que en él no se halle»

La ciudad de Surat le pareció no muy grande, pero de hermosos edificios. Los naturales del país "son de color membrillo cocho: pero no de mal gesto: mujeres y hombres van desnudos hasta media cintura por el gran calor, que alli hace. Llevan pendientes, muchas arrcadas, y gargantillas de oron. Partió de Surat en una frágil pero rápida embarcación de treinta remeros, especialmente indicada para burlar a los piratas que castigaban aquellas costas. En sólo una noche llegaron a la ciudad portuguesa de Damayn (Daman), y luego navegando siempre en cabotaje, siguieron ruta hacia Goa, pasando por diferentes lugares y reinos, como la de Chaul en el reino de Cananor, donde el sacerdote español fue testigo directo -y horrorizado- de la costumbre hindú de quemar viva a la esposa en la pira funeraria de su marido difunto, una circunstancia más que también viviría siglos después, el héroe literario de Jules Verne. Don Pedro escribe minuciosamente las ceremonias del rito, los cantos y la aparente tranquilidad de la viuda antes de arrojarse a la pira.

$\mathrm{Su}$ experiencia oriental había de acabar en Goa, la misma plaza donde más de cincuenta años antes empezara la suya aquel buen embajador de Felipe III. El capítulo XXX de su obra viene dedicado a describir la perla de la India portuguesa y su estancia en la ciudad. Recibido por el gobernador, pronto los jesuitas vinieron a recogerle, pues querían darle hospitalidad en su colegio de San Roque, uno de los edificios más bellos de la ciudad, "pues en fábrica, y arquitectura, si no excede, iguala al Colegio Romano". En su Casa Profesa visitó la tumba de San Francisco Javier, cuyo "cuerpo está entero, ... La cara la tiene, aunque algo desfigurada, como el mismo cutis: la barba de la misma suerte que si estuviera vivo", y mereció las atenciones del Padre Provincial.

Don Pedro Cubero alaba la belleza y fastuosidad de Goa y su región, aunque acepta con melancolía que ya no estaba en la misma prosperidad que antes, cuando era el "Emporio de todo el Oriente, pues alli acudían las naos, que venían del Japón, de la China, de Filipinas, del Mogor, de Arabia, del Ceylán, de Cambaya, de Achen, de Malacas, de Europa, de las Malucas, de Guinea, de Congo, de Cafrería, del Brasil, y de otras muchas partes del Asia, y del África: mas hoy ya todo esto se acabón. Las epopeyas imperiales habían terminado. Tal vez aún pensando en la mudanza de la fortuna, un día recibió aviso de que había llegado la nao que había 
de llevarle a Ceylán. Y una noche apacible, tras despedirse de sus amigos y hermanos, su buque atravesaba la barra de Goa, dejando a la derecha el castillo del Morro, y a la izquierda el de Vardés. Al amanecer se hallaron en alta mar. Su aventura por aquel Oriente Medio y alejado de los presidios de la India, por aquel Oriente transitado por los embajadores y comerciantes que iban hacia Irán, había terminado.

\section{Epílogo}

A mediados de un frío mes de enero del año 1680, el pueblo de Madrid celebraba ruidoso la entrada en la ciudad de la reina María Luisa de Borbón. Desde el Retiro al Alcázar, en la entrada al Prado de San Jerónimo, los Italianos, la Puerta del Sol, la Calle Mayor, la Puerta de Guadalajara, Santa María y la plaza del Palacio, se habían levantado cinco grandes arcos triunfales, decorados suntuosos y esculturas simbólicas de aquella abigarrada arquitectura efímera que tanto gustaba en la época ${ }^{20}$. Entre las músicas, los cantos y la alegría bulliciosa de la población que admiraba el lujo del cortejo, un curioso observador habría distinguido a un hombre fuerte, con la piel curtida por el sol y abundante melena oscura sobre los hombros, que vestido con la sencillez de un sacerdote secular, silencioso y pensativo entre gente festiva, observaba atento el paso de príncipes, duques y obispos con una ligera sonrisa. Aquel sacerdote miraba pensando a la vez en tantos otros cortejos por él vistos en países lejanos, desde Rusia hasta Irán y la India. Y recordó también, sin saber por qué, una lejana mañana en las playas del Caspio, cuando al tomar tierra junto al embajador del zar de Rusia, vio a tres niños bulliciosos que en cuclillas le observaban. Lo que Don Pedro ignoraba es que en aquel preciso instante también, tres jóvenes amigos paseaban por las playas de Derbent, hablando de los tiempos lejanos de su alegre niñez, de un día en el que un hombre de oscura melena les saludó amistoso, y ellos riendo se fueron corriendo y gritando la llegada del barco de Astrakán. Hacía de aquello más de siete años, y los ya jóvenes se preguntaban qué habría sido de aquel extraño, pero amistoso extranjero. No podían saber que él, tras cumplir una impresionante vuelta al mundo, en el lejano y frío Madrid de aquel año, rodeado de músicas, gritos y relinchos de caballos, pensaba melancólico en las playas de Derbent, y en tres niños curiosos y avispados, que sentados en cuclillas le habían dado con su sonrisa y sus alegres carreras, la mejor bienvenida a las tierras de Irán. 


\section{Pasajes de una vuelta al mundo...}

\section{Notas}

1 Cubero Sebastián, P. (1993): Peregrinación del mundo. Miraguano Ediciones / Ediciones Polifemo, Madrid. Para los recuerdos sobre la fortaleza de Derbent, pp. 196-197. Respeto en las citas de su libro la peculiar ortografía de la época y el autor. El soneto de Don Pedro Calderón de la Barca, que el autor incluyó en las primeas páginas de la edición original, dice así:

Si la nave de Argos, por primera

Náutica, que en el mar abrió camino

La admiración, la presumió Divino

Astro, añadido a la Celeste Esfera:

Si a la Nave Victoria por la entera

Vuelta del Orbe, Templos la previno

Del Oriente al Ocaso, alto destino,

Emuló al Sol en su veloz carrera:

¿Qué Templo? ¿Qué Astro? Construirá a una nave,

Que símbolo Apostólico de aquella

De Pedro, al mar fió Pedro Segundo?

Pero ¿qué Astro, qué Templo habrá más grave,

Que ser el Norte de la Fe su estrella,

$Y$ su Templo uno, y otro nuevo mundo?

Puede leerse en la p. 5 de la edición citada.

${ }^{2}$ La extensión que la vieja y prestigiosa Enciclopedia Universal Ilustrada Europeo Americana dedica en su volumen XVI, p. 860, a la entrada "Cubero y Sebastián (Pedro)" no llega siquiera a cubrir una columna. Sin embargo, existe un interesante artículo: ARCo, R. del (1947): «Pedro Cubero y Sebastián y su peregrinación de la mayor parte del mundo en el siglo XVII", Universidad XXIV, pp. 41-66.Véase también GARCÍA-ROMERAL PÉREZ, C. (1998): Bio-Bibliografía de viajeros españoles (siglos XVI-XVII). Ollero \& Ramos, Editores, Madrid, pp. 85-87.

${ }^{3}$ InVERNIZZI, A. (ed.) (2005): Il Genio vagante. Babilonia, Ctesifonte, Persepoli in racconti di viaggio e testimonianze dei secoli XII-XVIII. Edizioni dell'Orso, Alessandria. Sobre Pedro Cubero véase p. 346.

4 Cubero Sebástian, P. (1993): op. cit.: sobre Francia y París, pp. 28-36. No deja de ser sorprendente que el Delfín recibiera a Don Pedro Cubero, por más que le fuera introducido por Monsieur de Formamel, director del Seminario de Misioneros Apostólicos, donde estuvo acogido durante su estancia en la capital de Francia.

5 Cubero Sebastián, P. (1993): op. cit.: sobre el viaje por Italia, pp. 42-57.

6 Cubero Sebastián, P. (1993): op. cit., p. 103.

7 CABallero, O. (2005): «Julio Verne: Cien años (1905-2005). El propagandista de la revolución industrial", Leer 159 , pp. 36-46. Para una versión relativamente reciente de la novela, véase VERNE, J. (1984): Le tour du monde en quatre-vingts jours, Éditions Jean Claude Lattèsse, Paris. 
8 Peregrinación del mundo del doctor D. Pedro Cubero Sebastian, Predicador Apostolico, en Nápoles, por Carlos Porsile 1684. El volumen tenía 451 pp., casi 100 más que la primera edición española.

9 Peregrinaciones que he hecho de la mayor parte del mundo ....... desde España a las Indias Orientales, en Zaragoza, por Pascual Bueno, 1688, un volumen de $288 \mathrm{pp}$.

10 Descripción general del mundo y notables successos del, en Nápoles, por Salvador Castaldo, un volumen de 446 pp. La edición española llevaba el título de Descripcion general del mundo y notables successos que han sucedido en el: con la armonia de sus tiempos, rios, ceremonias, costumbres, y trages de sus naciones, y varones ilustres que en él ha avido, en Valencia, por Vicente Cabrera, impresor y librero, 1697, un volumen de $342 \mathrm{pp}$., con algunos grabados.

11 Cubero Sebastián, P. (1916): Peregrinación de la mayor parte del mundo. Tipografía de la Revista de Archivos, Madrid, 275 pp. (1943): Peregrinación del mundo. Atlas, Madrid, 174 pp. Finalmente la edición usada para este trabajo CuBERo SeBAstián, P. (1993): Peregrinación del mundo del Doctor D. Pedro Cubero Sebastián, Misionario Apostólico, Miraguano Ediciones / Ediciones Polifemo, Madrid, un volumen de 436 pp., con un pequeño prólogo sin firma, en el que se declara haber seguido la edición de Nápoles, a la que se añaden al final del volumen licencias, poemas, etc. "que no se incluyen en aquella, textos entre los que destaca el memorial dirigido a Carlos II por Pedro Cubero, donde resume sus viajes» (p. VII). El editor anónimo -que según un informante fue don Ramón Alba-, apunta haber modificado la ortografía sólo en algunos casos, respetando la puntuación y los nombres geográficos.

12 Para no recargar innecesariamente de citas este artículo, omito las referencias exactas de cada uno de sus comentarios. Como sigo rigurosamente su exposición, fácil será encontrar si se desea la localización exacta de sus observaciones en la obra de referencia, CUBERo SEBASTIÁN, P. (1993): op. cit.

13 Sobre las causas y efectos del problema cosaco, véase CHUDOBA, B. (1980): Rusia y el Oriente de Europa. Ediciones Rialp, S. A., pp. 99-101. Respecto a Stenka Razin, URE, J. (2002): Los cosacos, Editorial Ariel, S. A., pp. 73-85.

14 Según el catálogo del Prado, el cuadro $\mathrm{n}^{\circ}$ 644, pintado por Juan Carreño de Miranda, representa al embajador ruso Pedro Ivanowitz Potemkin, que vino a España en dos ocasiones, la primera en 1668, y la segunda en 1681. Sin embargo, preciso es notar que en el catálogo se dice que el cuadro debió ser pintado durante la segunda estancia. En todo caso, la vestidura del retratado nos permite evocar la figura del padre del gobernador de Astrakán. Véasè: Museo del Prado. Catálogo de pinturas 1996. Ministerio de Educación y Cultura, Madrid 1996, p. 66.

15 Es curioso que Don Pedro se dirija al holandés en francés, lengua que cuando años atrás llègara a París, desconocía por completo. Como no hay por qué dudar de su relato, hemos de suponer que en el curso de su largo viaje, que ya duraba varios años, hubo de aprender al menos lo suficiente como para entenderse.

16 El texto del memorial puede leerse en la edición de la obra de Don Pedro Cubero Sebastián que cito en las notas precedentes: Cubero Sebastián, P. (1993): op. cit., pp. 415-429. Se trata de un resumen muy bien hecho, cuya lectura proporciona una rápida idea del viaje y sus circunstancias. El texto en sí y el recurso a presentar dicho memorial al rey evidencia que Don Pedro Cubero era plenamente consciente del enorme mérito personal que su aventura suponía, y consideraba de justicia que en sus achaques y desvalimiento le auxiliase el rey. 


\section{Pasajes de una vuelta al mundo...}

17 INVERNIZZI, A. (2005): op. cit., pp.158 -395, para la antología de viajeros del siglo XVII. En la segunda mitad, el número de viajeros franceses supera con creces a los de cualquier otra nación europea.

18 INVERNIZZI, A. (2005): op. cit., pp. 303-327.

19 INVERNIZZI, A. (2005): op. cit., pp. 328-334 y 342 respectivamente.

20 Don Pedro Cubero describe con todo cuidado la decoración de las calles madrileñas y el cortejo que acompañaba a la reina María Luisa de Orleáns, el sábado 13 de enero de 1680 , acontecimiento que tuvo ocasión de contemplar recién llegado a la capital, y al que dedica el capítulo último de sus recuerdos. Véase Cubero Sebastián, P. (1993): op. cit., pp. 356-389. 